J. Roger Maltby MB BCHIR FFARCS FRCPC, Dibya S. Malla MB FRCOG, Hira Dangol MB MRCOG

\title{
Open drop ether anaesthesia for Caesarean section: a review of 420 cases in Nepal
}

Anaesthesia for Caesarean sections performed during 1982-83 at the Women's Hospital in Kathmandu, Nepal is reviewed, In a twelve-month period 535 Caesarean sections were performed, representing 7.36 per cent of 7,263 deliveries. Many pregnant women in Nepal do not have antenatal care and the mean haemoglobin of these

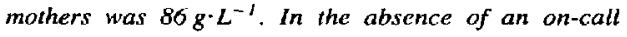
anaesthetist for obstetrics, more than 90 per cent of the anaesthetics were given by junior obstetric residents, using open drop diethyl ether without endotracheal intubation. Eleven patients developed postoperative chest infection; in none of these was there any suggestion of inhalation of gastric contents and all recovered uneventfully. Of the 18 maternal deaths in the 7,263 delivereies during this period, one occurred during Caesarean section. This was due to uncontrollable haemorrhage and was not attributable to the anaesthetic. For poor risk patients, and in unskilled hands, diethyl ether remains a remarkably safe anaesthetic.

Key words

ANAESTHESIA: obstetric; ANAESTHETICS, VOLATILE: diethyl ether; COMPLICATIONS: preoperative anaemia.

From the Department of Anaesthesia, University of Calgary, Calgary, Alberta, and Department of Obstetrics, Maternity Hospital, Kathmandu, Nepal

Address correspondence to: Dr. J.R. Maltby, Department of Anaesthesia Foothills Hospital at the University of Calgary, 1403-29th Street N.W., Calgary, Alberta, Canada T2N 2 T9.
The Women's Hospital in Kathmandu has the only major obstetrical unit in Nepal, a country of 16 million people. It has a staff of seven specialist obstetrician-gynecologists and 14 medical officers. Ninety-three per cent of anaesthetics for Caesarean section, in which the type of anaesthetic was specified, in the period under review, were given by medical officers. These physicians have completed their medical training and internship abroad and work in government hospitals under the direction of a specialist. Those on the obstetric service are taught by the specialist obstetricians how to give open drop ether anaesthesia. They have no formal postgraduate training in anaesthesia. The use of "Boyle's" type anaesthetic gas machines, with techniques involving muscle relaxant drugs and tracheal intubation, is considered too dangerous for use by non-anaesthetists.

This situation exists because there are only seven trained anaesthetists in the entire country, all of whom work at other hospitals in Kathmandu. Some of these, following a night on call, provide service at the Women's Hospital for elective gynaecological surgery and occasionally for elective Caesarean section. There is no trained anaesthetist on call for obstetric emergencies.

The patients included in this review cannot be compared with those in a Canadian obstetric unit. Over 7,000 mothers are delivered each year, many of whom receive little or no antenatal care. Diet during pregnancy is often inadequate and this, combined with intestinal parasites, leads to severe anaemia. Travel is difficult because of the mountainous terrain and lack of roads and it is not uncommon for a fetus to have been dead for days before the mother reaches the hospital.

Major obstetric complications, often compounded 
by long delays in arriving at the hospital, are common. Blood for transfusion may be difficult to obtain in an emergency. Heating facilities in the operating theatres are minimal. In the winter months, the theatre temperature may sometimes be as low as $7^{\circ} \mathrm{C}$ and hypothermia in newborn infants is a major problem.

This paper presents the results of a retrospective study of 420 Caesarean sections performed under general anaesthesia. Open drop ether was administered by Schimmelbusch mask without endotracheal intubation. Particular reference is made to maternal safety.

\section{Methods}

During a twelve-month period (1982-83) details of all Caesarean sections performed were recorded in a log book. These included matemal age and parity, indications for surgical intervention, fetal outcome, operative and postoperative maternal complications, and the name of the anaesthetist, for 535 patients. If the anaesthetist was one of the specialists (who never use open drop ether) the case was excluded from review of maternal complications and infant Apgar scores. Preoperative maternal haemoglobin and Apgar scores were obtained from the case notes. Conditions for filing and storing individual patient records were far from ideal and not all pertinent information was recorded in every chart. Nevertheless, the charts of 420 mothers who received open drop ether were reviewed. Maternal haemoglobin values were recorded for 376 patients, Apgar score at one minute for 405 and at five minutes for 371 patients.

Results were analysed using Student's unpaired t-test and analysis of variance. Differences where $p \geq 0.05$ were not considered statistically significant.

\section{Anaesthetic technique}

All patients received intramuscular atropine $0.6 \mathrm{mg}$ preoperatively. Pre-eclamptic patients also received diazepam $5 \mathrm{mg}$ intravenously before induction. Antacids were not given preoperatively, nor was a "wedge" used to produce left uterine displacement. If an intravenous cannula was available, an infusion might be started before induction of anaesthesia. If only needles were available, the infusion was started after induction to avoid dislodgement if the patient struggled during induction.
The patient's eyes were covered by a towel and ether was poured onto a gauze-covered Schimmelbusch mask. This was initially held slightly above the towel and gradually lowered as anaesthesia was induced. When the patient was breathing regularly and the pupils were beginning to dilate, an oropharyngeal airway was inserted.

Operating conditions were usually satisfactory, with good muscular relaxtion. The time from the start of induction of anaesthesia to delivery of the infant was approximately ten minutes. After delivery, the amount of ether poured was reduced, both in frequency and amount, so that by the end of the procedure the patient was very lightly anaesthetised.

\section{Results}

\section{Indications for Caesarean section}

The commonest indications for Caesarean section were cephalopelvic disproportion (35 per cent), fetal distress (21 per cent), placenta previa and abruptio placentae ( 16 per cent), shoulder and hand prolapse (eight per cent), cord presentation or prolapse (five per cent), prolonged labour (four per cent), postmaturity and failed induction (three per cent) and breech presentation (three per cent). The remaining five per cent included fulminating preeclamptic toxemia, cervical dystocia, and face and brow presentations. Seventy per cent of the procedures were classified as emergencies.

\section{Preoperative haemoglobin}

The distribution of haemoglobin concentrations is shown in Table $\mathrm{I}$. The mean was $89 \mathrm{~g} \cdot \mathrm{L}^{-1}$ and the range from 41 to $144 \mathrm{~g} \cdot \mathrm{L}^{-1}$. One-third of the patients had a haemoglobin concentration below $80 \mathrm{~g} \cdot \mathrm{L}^{-1}$ and eight per cent $60 \mathrm{~g} \cdot \mathrm{L}^{-1}$. The degree of anaemia was remarkably consistent, with respect to both age and parity. Maternal age, but not increasing parity, appeared to be associated with a slightly higher incidence of severe anaemia (haemoglobin $\left.<60 \mathrm{~g} \cdot \mathrm{L}^{-1}\right)$, although the overall degree of anaemia showed no significant differences among the various groups $(p>0.05)$. Despite the high incidence of anaemia only five per cent of patients received preoperative or intraoperative blood transfusions.

\section{Maternal outcome}

In the 535 Caesarean sections under review there 
TABLE I Haemoglobin concentrations related to age and parity

\begin{tabular}{|c|c|c|c|c|c|c|}
\hline & & \multicolumn{4}{|c|}{ Haemoglobin $g^{\cdot L^{-1}}$} & \\
\hline & & $41-60$ & $61-80$ & $81-100$ & $>100$ & \\
\hline \multicolumn{2}{|c|}{ Age (years) } & \multicolumn{4}{|c|}{ Percentage of patients } & Mean $H b \pm S D^{*}$ \\
\hline $15-24$ & $(n=149)$ & 7 & 27 & 50 & 16 & $86 \pm 16$ \\
\hline $25-34$ & $(n=188)$ & 6 & 26 & 49 & 19 & $86 \pm 17$ \\
\hline 35 or more & $(n=39)$ & 15 & 15 & 51 & 17 & $84 \pm 18$ \\
\hline \multicolumn{7}{|l|}{ Parity } \\
\hline 1 & $(n=126)$ & 8 & 20 & 52 & 21 & $88 \pm 17$ \\
\hline $2-4$ & $(n=190$ & 7 & 27 & 48 & 17 & $85 \pm 16$ \\
\hline 5 or more & $(n=60)$ & 8 & 32 & 48 & 12 & $86 \pm 16$ \\
\hline
\end{tabular}

* Mean haemoglobin $\mathrm{g} \cdot \mathrm{L}^{-1} \pm$ standard deviation for each group according to age or parity.

was one matemal death. This occurred during open drop anaesthesia and was due to massive bleeding from antepartum haemorrhage. The number of patients who vomited during induction or recovery was not recorded. There were eleven postoperative chest infections, an incidence of two per cent, which could not be correlated with any untoward events during surgery. Deep wound infection occurred in 20 per cent of patients, of whom one quarter required excision of infected tissue and resuturing under general anaesthesia.

\section{Fetal outcome}

Table II shows fetal outcome and Table III the causes of neonatal death for the entire series of 535 cases, including those in which the anaesthetic was given by a specialist anaesthetist. Some Caesarean sections were preformed to save the mother's life, even though the fetus was known to be dead. The

TABLE II Fetal outcome

\begin{tabular}{lcc}
\hline & Number & Percent \\
\hline Live & 461 & 86 \\
Stillbirth & 44 & 8 \\
Neonatal death & 30 & 6 \\
\hline
\end{tabular}

Fetal outcome in 535 Caesarean sections.
TABLE III Causcs of neonatal death

\begin{tabular}{lcc}
\hline & Number & Per cent \\
\hline Prematurity & 13 & 44 \\
Asphyxia & 11 & 37 \\
Infection & 4 & 13 \\
Congenital abnornality & 1 & 3 \\
Rhesus incompatibility & 1 & 3 \\
\hline
\end{tabular}

$\mathrm{n}=\mathbf{3 0}$

overall stillbirth rate was 8.2 per cent; prematurity was the leading cause of death. Apgar scores at one and five minutes following open drop ether anaesthesia are shown in Table IV. Methods of resuscitation included clearing of the airway, manual stimulation, mouth to mouth resuscitation, and intermittent positive pressure ventilation by mask. Endotracheal intubation was only recorded in one case.

\section{Discussion}

During the past two decades in North America there has been a dramatic increase in the popularity of regional anaesthesia for Caesarean section. This is partly due to anaesthetists' concern over the risk of pulmonary aspiration of acid gastric contents during obstetric general anaesthesia and partly to the

TABLE IV Apgar scores

\begin{tabular}{|c|c|c|c|c|c|c|c|c|c|c|}
\hline \multirow[b]{2}{*}{ Apgar score } & \multicolumn{5}{|c|}{1 minute } & \multicolumn{5}{|c|}{5 minutes } \\
\hline & $1-2$ & $3-4$ & $5-6$ & $7-8$ & $9-10$ & $1-2$ & $3-4$ & $5-6$ & $7-8$ & $9-10$ \\
\hline Infants & 35 & 37 & 21 & 5 & 1 & 0.5 & 10 & 33 & 46 & 11 \\
\hline
\end{tabular}

Apgar scores (excluding stillbirths) at 1 minute and 5 minutes of 420 mothers who received open drop ether anaesthesia. 
mothers' desire to see their babies bom and for fathers to share that experience.

In third world countries few doctors have formal training in anaesthesia. Intravenous fluids, blood, and plastic intravenous cannulae may not be available for rapid fluid administration should hypotension occur. Whether spinal anaesthesia would be safer than general anaesthesia in such circumstances is uncertain. In a major review of obstetric anaesthesia deaths in 1956 Lock et al. attributed nearly as many deaths to spinal shock as to aspiration of stomach contents during general anaesthesia.'

The use of open drop anaesthesia in obstetrics using diethyl ether is safer than many anaesthetists might believe, ${ }^{2}$ and may be the technique of choice in the conditions we have described. In one large city 3,048 open drop anaesthetics were given during $1942-1952$ in obstetric patients' homes, without mortality. ${ }^{3}$ Our review of 420 open drop ether anaesthetics without endotracheal intubation for Caesarean section confirms that it is a surprisingly safe technique when maternal mortality and major morbidity are assessed. Not only were the anaesthetics administered by junior doctors with no formal anaesthetic training, but most of the mothers were moderately to severely anaemic, blood was not readily obtained for emergency cases, and most patients followed the Nepalese tradition of eating plenty of food during labour. It is not our purpose to advocate this technique when a specialist anaesthetist is available, with a full range of anaesthetic drugs and equipment. Unfortunately, in many parts of the world that situation does not exist.

In developed countries the mean haemoglobin concentration in women in late pregnancy is 122 $\mathrm{g} \cdot \mathrm{L}^{-1} .^{4}$ In Calgary $(1100 \mathrm{~m})$, which is at approximately the same altitude as Kathmandu $(1400 \mathrm{~m})$, the mean haemoglobin concentration of women undergoing Caesarean section is $132 \mathrm{~g} \cdot \mathrm{L}^{-1}$. In Kathmmandu it was $86 \mathrm{~g} \cdot \mathrm{L}^{-1}$. Many anaesthetists would consider such a degree of anaemia unacceptable. If $100 \mathrm{~g} \cdot \mathrm{L}^{-1}$ is considered the safe lower limit for general anaesthesia, 80 per cent of patients in this series were "unfit" for anaesthesia and surgery.

In Nepal the medical officer must either give an anaesthetic or not treat the patient, the latter being clearly unacceptable. However, patients in chronic renal failure, with haemoglobin concentrations similar to those in Table I, tolerate anaesthesia well.
Furthermore, transfusion of severely anaemic patients can precipitate heart failure from volume overload. ${ }^{5}$ It may be safer practice not to transfuse the most severely anaemic patients preoperatively because of this risk. The only death in the 535 patients reviewed was not caused by anaemia itself but by uncontrollable antepartum haemorrhage.

In obstetric anaesthesia there is always concern that pulmonary aspiration of gastric contents can occur in the absence of a cuffed endotracheal tube. The danger may not be as great as is usually taught. ${ }^{6}$ In one university centre in England, inhalation induction of anaesthesia using ether to a depth adequate for tracheal intubation was used for many years, whenever there was a risk of vomiting and especially in cases of intestinal obstruction. ${ }^{7}$ Over a period of 14 years 250,000 anaesthetics, elective and emergency, were given by anaesthetists with varying degrees of skill and experience. During that time no patient died from inhalation of vomit during induction of anaesthesia. Only in deep ether anaesthesia are the patient's own protective reflexes, especially the carinal reflex, totally abolished. ${ }^{8}$

The confidence that tracheal intubation would prevent the inhalation of gastric contents during obstetric anaesthesia has not been justified by successive British enquiries into maternal mortality. During the years $1955-63^{9-11}$ the number of deaths from this cause varied between 14 and 17 per triennium and criticism was directed at the absence of planned intubation. During the next triennium, $1964-66,{ }^{12}$ not only was intubation planned in all the patients who died but the number of deaths increased to 26. By 1976-78, although the number of mothers who died from inhalation of gastric contents had fallen below the 1955-63 level, the deaths of at least nine others were attributed to difficult intubations. This report comments that, even when intubation is planned, an adequate drill for difficult intubation must be taught, and that "anaesthesia to a depth classified by Guedel as III(i) or III(ii) prevents vomiting even without an endotracheal tube and is less harmful to the neonate than having no mother."13

During the past 30 years there have been advances in anaesthetic practice, each of which should reduce the risks of regurgitation and aspiration of gastric contents during general anaesthesia. In 1961 Sellick described the technique of cricoid pressure to prevent passive regurgitation of gastric contents 
into the pharnyx. ${ }^{14}$ Antacids, such as magnesium trisilicate ${ }^{15}$ and sodium citrate, ${ }^{16}$ have been used in an attempt to neutralise gastric acid. More recently histamine $\mathrm{H}_{2}$ receptor antagonists have been used to reduce secretion and increase gastric $\mathrm{pH} .^{17,18} \mathrm{De}$ spite these efforts to eliminate the risks, deaths continue to occur from the acid aspiration syndrome. ${ }^{19}$ None of these preventive measures was used in our patients.

Vomiting during light anaesthesia is preceded by swallowing, heaving movements, and breath holding. This, rather than silent regurgitation, is the sequence of events which may occur during an ether induction. There is usually time to turn the patient on her side and head down before the actual ejection of vomit occurs. The occurrence of fatal aspiration of gastric contents has always been infrequent. Therefore the 420 open drop ether cases reviewed is too small a number from which to draw conclusions, except to dispel fears that the technique is indefensibly dangerous.

Many of the infants had low Apgar scores, probably because many of them were partially anaesthetised. This is not necessarily dangerous because diethyl ether is a respiratory stimulant. ${ }^{20}$ The Apgar score rarely exceeds seven at one minute because there may be no active motion, rarely a strong cry, and little response to stimulation. The mortality rate of premature infants was high. Facilities for long-term ventilation were not available and, in winter, the lack of heat in the operating theatre commonly led to hypothermia.

Open drop ether is unlikely to be used again in Canada. However, for situations where there is no trained anaesthetist and very sick patients we should not condemn it until another technique, tested under similar conditions, is proven to be safer, not only for the fetus but also for the mother.

\section{Acknowledgements}

The authors wish to thank the Maternity Hospital, Kathmandu for permission to publish this paper; Shanti Vaidya and Indira K.C. of the Statistics Section, Maternity Hospital, Kathmandu, Nepal, and Mrs. Margaret Maltby, for patient record retrieval; and Mrs. Caroline Harris for secretarial assistance.

\section{References}

I Lock FR, Greiss FC. The anesthetic hazards in obstetrics. Am J Obst Gynec 1955; 70: 861-75.

2 Hopkin $D A B$. Open drop ether versus relaxant techniques in obstetrics. In: Rupreht J, van Lieburg MJ, Lee JA, Erdmann W., eds. Anaesthesia; Essays on its history. Berlin: Springer-Verlag, 1985; 95-8.

3 Parker RB. Matemal deaths from aspiration asphyxia. Br Med J 1956; 2 : 16-9.

4 Llewellyn-Jones $D$. Fundamentals of obstetrics and gynaecology. Vol. I, Obstetrics, 3rd ed. London: Faber and Faber, 1982; 47.

5 Slawson $K B$. Anaesthesia for the patient in renal failure. Br J Anaesth 1972; 44: 277-82.

6 Phillips $O C$. An endotracheal tube is not mandatory when general anesthesia is given to a parturient. In: Eckenhoff JE (Ed.) controversy in Anesthesiology. Philadelphia: WB Saunders, 1979; 123-8.

7 Inkster JS. The induction of anaesthesia in patients likely to vomit, with special reference to intestinal obstruction. Br J Anaesth 1963; 35: 160-7.

8 Dripps $R D$, Eckenhoff $J E$, Vandam $L D$. Introduction to Anesthesia; 6 th ed. Philadelphia: WB Saunders, 1982; 197.

9 Ministry of Health. Report on confidential inquirics into maternal deaths in England and Wales 19551957. London: Her Majesty's Stationery Office $1960 ; 37-8$.

10 Ministry of Health. Report on confidential inquiries into matemal deaths in England and Wales 19581960. London: Her Majesty's Stationery Office $1963 ; 32-5$.

11 Ministry of Health. Report on confidential inquiries into maternal deaths in England and Wales 19611963. London: Her Majesty's Stationery Office 1966 ; 44-7.

12 Department of Health and Social Security. Report on confidential inquiries into maternal deaths in England and Wales 1964-1966. Landon: Her Majesty's Stationery Office $1969 ; 68-75$.

13 Department of Health and Social Security. Report on confidential inquiries into maternal deaths in England and Wales 1976-1978. London: Her Majesty's Stationery Office 1982; 77-88.

14 Sellick BA. Cricoid pressure to control regurgitation of gastric contents during anaesthesia. Lancet 1961 ; 2: 404-6.

15 Taylor G, Pryse-Davies $J$. The prophylatic use of antacids and prevention of acid-pulmonary-aspira- 
tions syndrome (Mendelson's syndrome). Lancet 1966; 1: 288-91.

16 Lahiri SK, Thomas TA, Hodgson RMH. Single-dose antacid therapy for the prevention of Mendelson's syndrome. Br J Anaesth 1973; 45: 1143-6.

17 Dundee JW, McGowan WAW, Moore J. Cimetidine in the first stage of labour. Preliminary results. Anaesthesia 1979; 34: 118.

18 McCaughey W, Howe JP, Moore J, Dundee JW. Cimetidine in elective Caesarean section. Anaesthesia 1981; 36: 167-72.

19 Taylor $G$. Acid pulmonary aspiration syndrome after antacids. Br J Anaesth 1975; 47: 615-7.

20 Dripps $R D$, Severinghaus $J W$. General anaesthesia and respiration. Physiol Rev 1955; 35: 741-75.
Résumé

L'anesthésie pour césarienne accomplie en 1982-83 d l'hôpital "Women's Hospital", Kathmandu, Nepal, est revue. Pour une durée de douze mois, 535 césariennes ont été accomplies représentant 7.36 pour cent des 7,263 accouchements. Plusieurs des femmes enceintes duNepal n'ont pas reçu de soins prénataux et l'hémoglobine moyenne de ces mères était de $86 \mathrm{~g} \cdot \mathrm{L}^{-1}$. En l'absence $d u^{\prime}$ un anesthésiste de garde en obstétrique, 90 pour cent et plus des anesthésies ont été données par le résident junior en obstétrique utilisant le diéthyl éther en goutte d'un circuit ouvert sans intubation endotrachéale. Onze patientes ont développé une infection pulmonaire postopératoire; chez aucune de ces patientes il n'y avait d'évidence d'aspiration bronchique et toutes se sont rétablies sans conséquence. Des 18 morts maternelles pour 7,263 accouchements pendant cette période, une est survenue lors d'une césarienne. Celle-ci était due à une hémorragie incontrôlable et non attributée d̀ l'anesthésie. Pour des patientes à pauvre risque et dans des mains non expertes, le diéthyl éther demeure un anesthésique remarquablement sécuritaire. 